\title{
Intrahepatocelluar Erythrocytes
}

National Cancer Institute

\section{Source}

National Cancer Institute. Intrahepatocelluar Erythrocytes. NCI Thesaurus. Code C147497.

The presence of red blood cells within hepatocytes of the liver parenchyma. 